\title{
A Decade of Working with the Working Crowd
}

\section{xtine burrough}

Professor and Area Head of Design + Creative Practice in the School of Arts, Technology, and Emerging Communication, The University of Texas at Dallas

\begin{abstract}
In this essay I narrate creative projects that disrupt or interfere with the Mechanical Turk platform. My place as an artist and employer in the elastic workforce since 2008 has given me a close and nuanced view of life online in the virtual workplace. The jobs I have created on the platform ask workers to perform athletic events, create videos, meditate, and talk back to Jeff Bezos. The materials I collect from the workers are integrated into art works that amplify the visibility of the workers and their unique voices. This article shows how those "underrated" humans in the Amazon economy are creative, thoughtful, and intelligent.
\end{abstract}

\section{INTRODUCTION}

In 2006 Amazon.com initiated a new job-board platform, Mechanical Turk (Mturk.com). At that time, I was creating projects that used the Web to facilitate exchanges in the real world. I learned of the terms "crowdsourcing" and "user-generated content" after I made Delocator.net, a website where people can locate independent coffee shops, and which relies on both content generated by its users (names and addresses of coffee shops) and the wisdom of the crowd (debates about which shops are "independent"). For that project, it was easy to find participants - people had strong feelings about coffee and the coffee industry, especially in 2005 when Starbucks was known for its colonizing tactics, and the press was interested in the quirky Web, coffee culture, and (yay or nay) Starbucks. For other projects, I could hardly engage the audience of fellow peers and artists, let alone the general public. So when I first visited Mturk.com, I saw its potential as a creative participant pool and wondered if it would be possible to make art by engaging (that is, hiring) the virtual workers on Mturk.com.

Ten years later, I believe it is possible, and that the politics of doing such a thing are embedded in the work of art and the role of the artist.

Since 2008 I have been creating participatory projects with workers on Mturk.com to disrupt the dehumanizing qualities of life in the virtual factory. While typical HITs, or "human intelligence tasks," on Mturk.com include labeling images, creating keywords, or writing captions, my tasks 
encourage workers to acknowledge their corporeal bodies. By requesting that workers perform physical jobs, I highlight a tension between the worker body and the metaphor of the ghost in the machine_resituated in Amazon's tagline, "artificial artificial intelligence." For instance, I have paid workers to create videos for an online alternative to the Olympic games for the Mechanical Olympics, light candles for people they have loved and lost for an installation and ongoing photo series $A$ Vigil for Some Bodies, co-create the book series A Penny for Your Thoughts, in which workers contribute a thought for a series of keywords, and to sit in meditation or chant for Mediations on Digital Labor. As time passed and the platform politics remained the same, my creative practice leaned towards activism in The Laboring Self and its companion workshop, $\underline{\text { Return }}$ to Sender, developed with Sabrina Starnaman. What follows is a description of a few of these projects carried out on MTurk and coupled with reflective writing from the working crowd on Amazon's platform.

\section{MECHANICAL OLYMPICS AS A CONCEPTUAL EXPERIMENT IN PLAYBOUR}

I learned of Mturk.com in the summer of 2008, just weeks before the Summer Olympics in Beijing. The buzz of the Olympics must have conflated in my mind with the question of whether it was possible to make art with virtual workers. The result was my first creative intervention on MTurk, the Mechanical Olympics (Figure 1). Instead of sorting images, labeling keywords, or doing some other mundane reading/writing task, workers who took my HIT (I will refer to these as "jobs") created Olympic-style video performances.

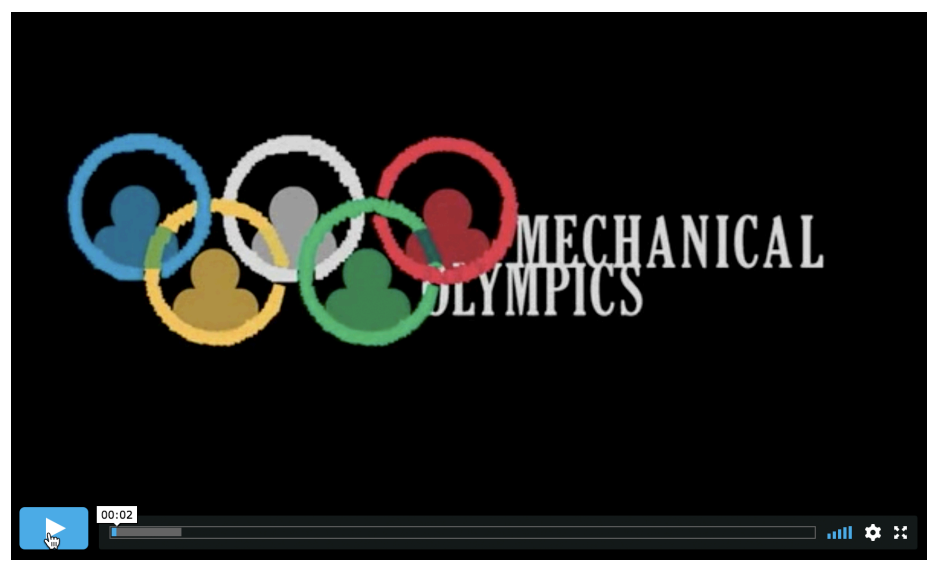

\section{Figure 1. Mechanical Olympics descriptive video, 2008-ongoing.}

To learn about Mturk.com, I initially signed up as a worker. In one hour of selecting images and keywords I earned a "reward" of 82 cents. I realized the potential of Amazon's platform as an unregulated virtual factory for piecework-style labor. After working on MTurk, I began to look for inspiration in works of art made with virtual workers. 
The artists and projects that were most influential centered on the politics of the platform. Andrew Ross describes how "people understand, more or less, what a sweatshop is, and also recognize that its conditions are unfair. By contrast, we have very few yardsticks for judging fairness in the salaried or freelancing sectors of the new, deregulated economy, where any effort to draw a crisp line around work and pay (not to mention work and play) seems to be in increasingly ineffectual" ("In Search of the Lost Paycheck," 25). Aaron Koblin's overtly exploitative The Sheep Market (2006) critiques Mturk.com - and what would come to be termed the "gig economy"1 during the financial crisis of 2009 - through its formal use of the platform. Koblin hired 10,000 workers to "draw a sheep facing to the left" for a reward of two cents (USD) for each drawing. ${ }^{2}$ Sheets of 20 drawings grouped together as adhesive stamps were sold on Koblin's website as fine art - the inflation in the price is part of the conceptual rattling on the doors of the virtual factory. Pablo Helguera might consider this an "unethical artistic action" which is "part of the role that art plays in challenging assumptions in society" (Education for Socially Engaged Art, xiv). While I admired Koblin's rigor, in the project I was about to create I wanted the work experience to look more like play; I could not put myself in a position to hire workers for pennies, even in the name of artethical or not. The politics of the platform were important to me in 2008, but they were not foregrounded in the Mechanical Olympics. I would make several other interventions before requesting that the workers engage in a politically-driven collaboration for The Laboring Self and Return to Sender.

Though I came to it after my first project with MTurk workers, Julian Kücklich's hybrid concept of playbour ${ }^{3}$ influenced my thinking during my formative years of art-making and intervention on the platform. Kücklich highlights the entanglement of work and play in digital entertainment industries where gaming platform owners commodify the "play" shared online by moddersindividual gamers who modify or extend games as a fun hobby. This blurred boundary between the unpaid play that becomes commodified into unpaid labor struck me as a possible dynamic on Mturk.com. The demographics of workers have been studied repeatedly via surveys on Mechanical Turk. ${ }^{4}$ Ipeirotis asked workers based in the United States and India (at the time, the two dominant demographics by location) why they complete tasks on Mturk.com. He found that twenty percent of Indian workers and twice as many American workers participate on Mechanical Turk because the tasks are fun. ${ }^{5}$ Employers exploit the nebulous boundary between play and labor for these workers. If I could turn my jobs into paid acts of play, I would disrupt the corporate ethos of playbour that Kücklich describes.

Stephanie Rothenberg and Jeff Crouse's mixed-reality performance Invisible Threads employed virtual workers on Second Life to facilitate the co-creation of jeans in the real world. ${ }^{6}$ Their 2008 activist project made visual the disparate economies for factory workers and owners. It also held performative elements in the process of participation, similar to what I imagined would happen in the worker responses to the job request I created for the Mechanical Olympics.

Since the interaction would begin on the platform, I considered the written instructions in my job description an element of conceptual art. Stanley Brouwn's This Way Brouwn and Sol LeWitt's 
wall drawings inspired my thinking about this part of the process. Brouwn asked passersby for their drawings directly, whereas LeWitt employed (exploited?) museum staff to carry out his "human intelligence tasks." In my case, the directions were posted to a digital job platform, and I had to set a rate of pay (Figure 2).

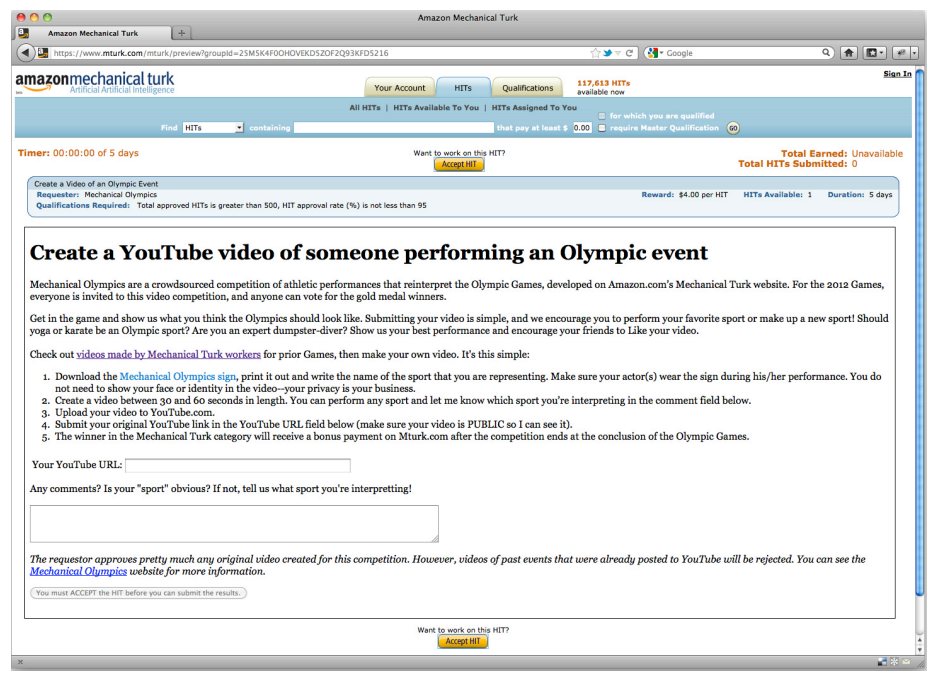

Figure 2. An early HIT placed for Mechanical Olympics in 2012 (Mturk.com underwent an update and earlier HITs were not archived.) During this version of the project I asked workers to interpret any sport for the online Olympics.

In 2008, most jobs were posted for pennies - one to ten cents per task was common. Few jobs were rewarded in dollars. I assumed that my request, to make a new video and post it to YouTube, would take at least ten minutes. Worker compensation is troubled by the global scale of the platform. Since there is no flexible method for payment on Mturk.com, I decided to offer a fair payment in US dollars (where the work of art originated), knowing this would mean over- or underpaying workers in other parts of the world. I offered \$3-\$4 per video, assuming that most people would be able to fulfill it in less than twenty minutes. ${ }^{7}$ They were consistently at the top of the list when jobs were sorted by reward amount from highest to lowest. In terms of writing and posting the jobs, my experience as an arts educator, starting in the mid-1990s, influenced how I wrote a creative job or delivered a set of specifications ("design specs"). So writing a job to be flexible in its potential for creative solutions, for a fair "reward" amount (or pay), is integral to my performance in the requester role on the site.

Since each video would be a part of the gestalt experience, an online version of the Olympic Games, I asked each worker to wear the Mechanical Olympics signage. This one visual element would appear in each video (Figure 3).

The first time I executed this project, I had no plan or potential for exhibition or general audience, outside of the workers on Mechanical Turk. I hosted the 2008 Mechanical Olympics on a blog, 
where I embedded videos of the workers performing a specific sport—one women's and one men's for each day of the Games - and a voting poll to accompany each set of videos (Figure 4). In lieu of medals, the two daily winners received a fifty-cent bonus payment on Mturk.com. I had some small successes in finding places for the project to be reviewed ${ }^{8}$ or honored, ${ }^{9}$ and these acknowledgements gave me enough confidence in the work to continue its development.

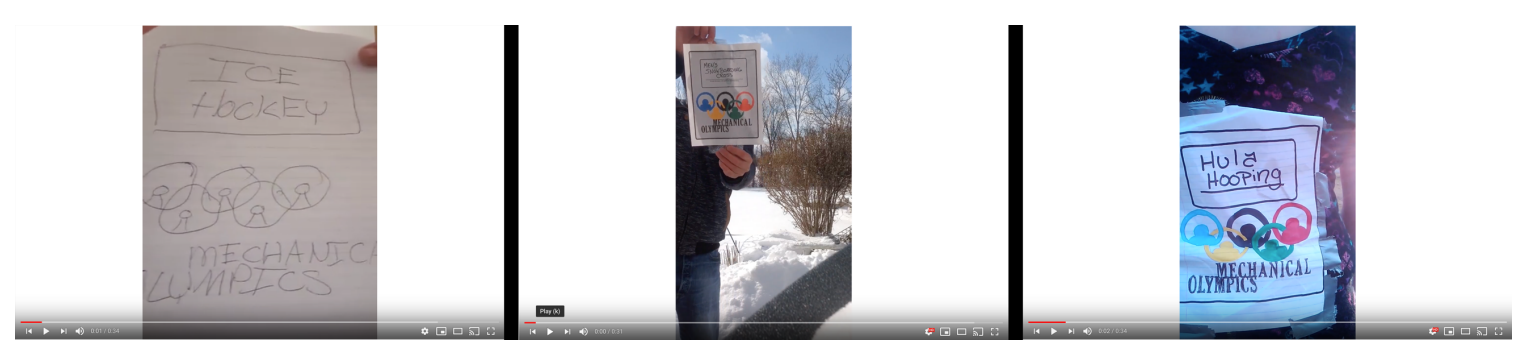

Figure 3. Workers wear the Mechanical Olympics signage—my favorites are hand-drawn reinterpretations of the digital sign I created.

Figure 4. The first versions of the Mechanical Olympics took place on a blog where posts and voting polls were published on the days of the Olympic Games.

In 2009-a non-Olympic year, as I now organize chunks of time in my life-I met Sarah Perks during a roundtable ISEA discussion on curating participatory art practices. When I told her about my experiments with the Mechanical Turk workers and the Olympics, she saw a potential for this 
project to expand to other participants/audiences. Since the Olympic Games would be hosted in London in 2012, the Cultural Olympiad was ready to fund projects that combined art and sport for cultural event programming throughout the UK. Through this lens, the Mechanical Olympics morphed into the Mechanical Games for festivals, Abandon Normal Devices at Cornerhouse (Manchester, 2010) and Looping the Loop (Media City, 2011) in the UK. These versions of the project de-emphasized workers on Mechanical Turk and brought the performative qualities of the project to various communities in and near Manchester. I loved working from afar and seeing how people in Manchester, such as a group of senior citizens from Front Row Newton Heath Group in New East Manchester and Zest, the Wise Move Dance Group from Didsbury, the Spartans Gay Rugby Team, and so on, would reinterpret the Olympic Games (Figure 5). But the workers on Mturk.com continued to hold my attention.

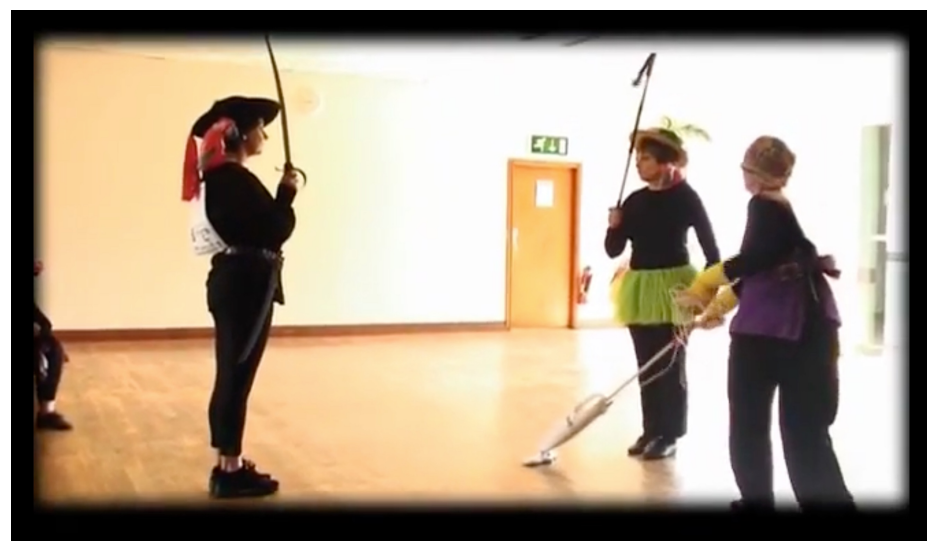

\section{Figure 5. The Wise Move Dance Group performs "Fencing” for the Mechanical Games in Abandon Normal Devices, Cornerhouse, Manchester, UK 2010.}

From my first experiment in 2008, to variations on the Games, and to the most recent edition of Winter 2018, every version of this project had contributors who are both playing and producing a form of labor as creative participants. When I first started my collection of interventions on Mturk.com, I thought I was making a single experiment that would mark a moment in Internettime. Because there were creative interventions that showed how Murk was exploitative, as well as articles in reputable popular publication ${ }^{10}$ and academic conferences, ${ }^{11}$ I thought Mturk.com would be a short-lived Internet fad like ICanHasCheezburger or Friendster.

I was wrong.

\section{Meditation on Mturk.com}

Starting in 2012 I executed the Mechanical Olympics on YouTube because the "Like" button pervaded social platforms. By 2015 I had programmed it four times. My exploratory phase was over. I continue to facilitate the project-programming the event has become as mechanical as posting HITs and retrieving data on Mturk.com. 
I proposed developing a new work for the Project Room at Grand Central Art Center, where John Spiak brought his curatorial livelihood to Santa Ana, California. In short, perhaps tangentially inspired by Jerry Seinfeld and Larry David's 1990s television show about "nothing" and everything all at once, I proposed nothing. ${ }^{12}$ That is, in my first experiment I paid workers to play; in this one, I would pay workers to do nothing.

For Mediations on Digital Labor I hired 50 workers to do nothing for one to five minutes. I assumed they might meditate or they might take a nap, or they might collect the money and not take a break at all. I left a response field and asked the workers to write me a description of their experience. Like the sitcom Seinfeld, this job was actually about something (a writing task) and not entirely about nothing; but there was space for creative potential.

\section{Making "nothing" visible}

The workers and I experience meditation similarly: we are restless, we are self-conscious, we have a hard time in quietness. Stillness is hard. I knew I wanted to use the sentiments gathered from the workers - a text, in its own right - as a central component in the exhibition. I had a vision of the workers' words chalked on the black tiled floor. When the public would walk into the room, they would obscure the words on the floor. This activity seemed appropriate, as the primary visual reference to the workers would become invisible when the general public entered the space.

Visibility is one of the hardships in the gig economy - how do anonymous, decentralized workers have a voice when they are reduced to playing the role of the ghost in the machine? I selected quotes from the workers about their meditation or work-break experience and set to creating a typographic pattern across the project room floor, including their thoughts and worker ID numbers. It took me fifty hours to cover the floor in chalk (Figure 6). There was a meditative quality to this work, and the way in which my role in the project became an evident, but invisible, physical labor also seemed fitting.

In a second job, I asked the workers to chant "Om," and collected 30 videos. USB drives hung across the gallery walls, each one containing a video file submitted by a chanting worker. In the center of the room was a digital viewing station where the public could see the workers' videos and hear their chant on a constant loop (Figure 7). During the exhibition (June-August) I offered anyone who would re-chalk the floor for thirty minutes a worker Om chant (Figure 8). 


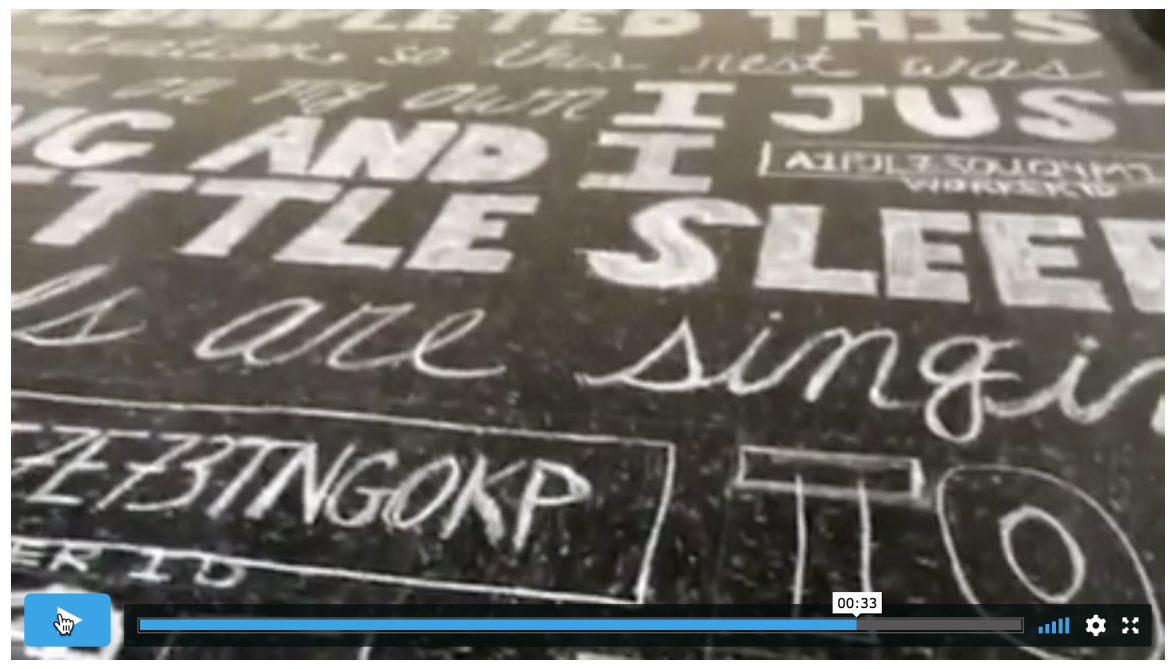

Figure 6. Chalking the floor of the Project Room at Grand Central Art Center (Santa Ana, California) for Mediations on Digital Labor, 2015.

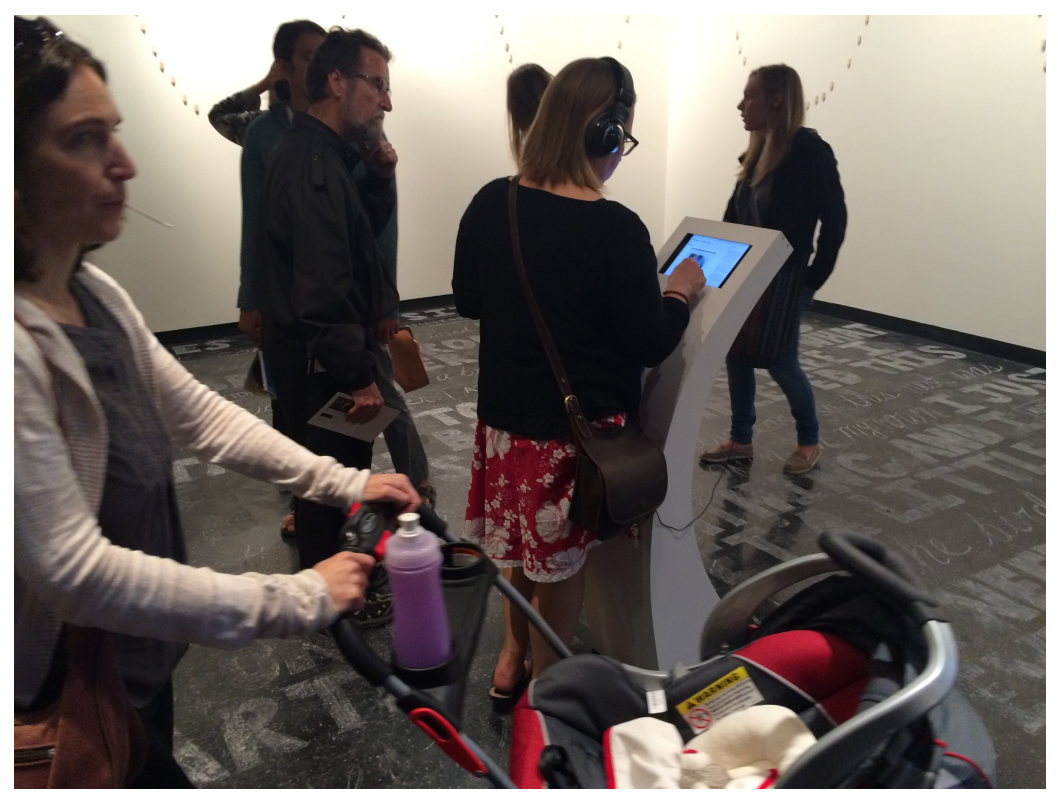

Figure 7. Installation View, Mediations on Digital Labor, Santa Ana, California, 2015. 


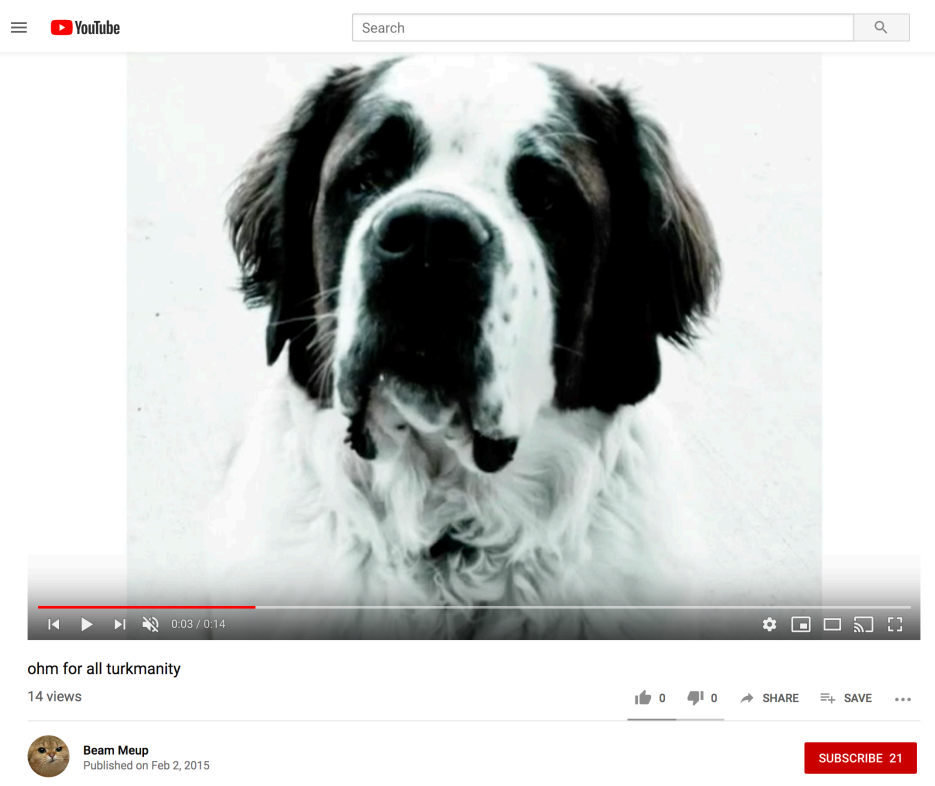

Figure 8. Mechanical Turk worker chants "Om" for a collection of worker chants, 2015. The other workers did not submit chanting dogs.

Only ten people re-chalked the floor. Gaining audience participation is even more difficult than stillness.

\section{The Laboring Self and Return to Sender: Collecting Worker Reflections}

In 2015 I began collaborating with a UT Dallas colleague, Sabrina Starnaman. We saw parallels between our academic interests: her studies in progressive-era women's literature and my participatory art practice with virtual workers. Since workers in literature of the Industrial Era were often reduced to "hired hands," for our first project the worker hand became the visual connective tissue between an exhibit and a workshop series.

The Laboring Self exhibition and Return to Sender workshop were developed for an artist residency at the Dallas Museum of Art's Center for Creative Connections (C3, October 2017-January 2018). Our project was inspired by the following question: How can digital laborers protest against management when they are decentralized and cannot jam the machines with their bodies because they are the machines? The project started with a new post on Mturk.com that asked workers to answer one question $(\mathbf{Q})$ and submit one photograph $(\mathbf{P})$ :

Q. How does virtual work on Mturk.com affect your body?

P. Submit a tracing of your hand along with a measurement from your wrist to the top of your middle finger.

To determine the payment fee, we ran a pilot version with a group of five workers. ${ }^{13}$ Once we received sentiments and hand tracings, my work would begin. For three months of a participatory 
exhibition in a space that receives classes on field trips, families, and museum-goers (we had more than 50,000 visitors between October and January), I created or directed the production of 1200 cardboard hands laser-cut from Amazon boxes.

\section{The Laboring Self}

I knew I would need a production assistant. I hired my student, Delaney Conroy, to cut worker hands from Amazon boxes (Figure 9). Then I hired two more students, Letícia Ferreira and Lizz Atwater, who embroidered some of the cardboard hands. We would start a participatory installation with a series of embroidered cardboard hands (Figure 10).

In the exhibition space, "Hired Hands" sprawled across one wall where hands cut from Amazon boxes held worker and exhibition participant sentiments (Figure 11). The installation grew throughout the exhibition as participants made and added more cardboard hands. On blank, actualsize worker hand cut-outs participants answered the same question as virtual workers about how working affects their bodies. Using the laser cutter and just the right font, ${ }^{14}$ I punched holes in larger cardboard hands to spell out words collected from the worker sentiments, such as "achey," "dull," "pain," and "hunch." Some participants embroidered the larger hands with yarn and plastic needles. Finally, we invited participants to trace their hand on a sheet of paper (creating symmetry between the exhibition experience and the tasks we asked of the MTurk workers) and then create a crayon rubbing of an embossed quote of their choice from one of six wooden disks (Figure 12). These quotes about or inspired by labor were selected from books and poems of the Industrial Era. ${ }^{15}$ The paper hands were "rewards" (to use the language of MTurk) for participants.

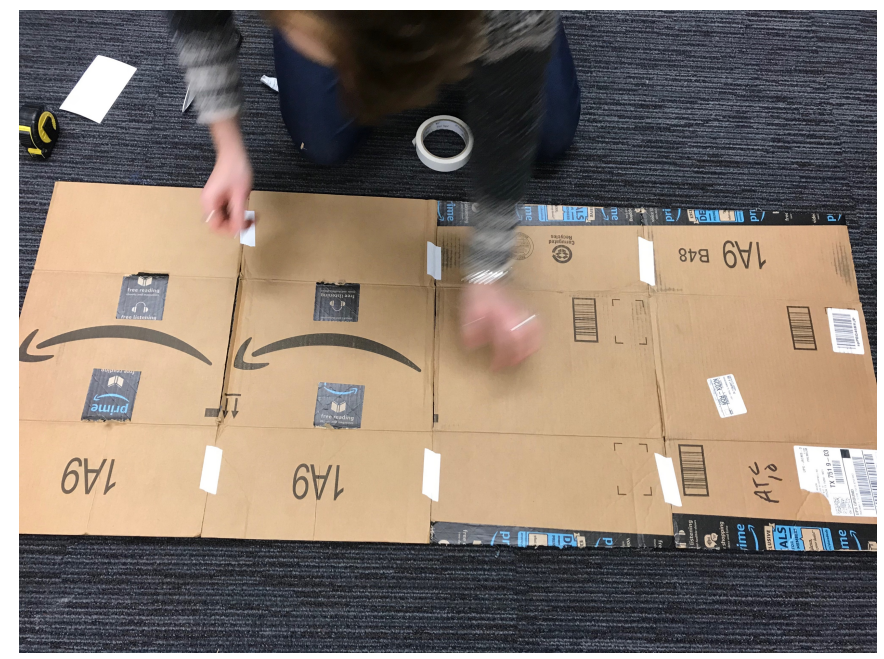

Figure 9. Delaney Conroy unfolds, cuts, and tapes Amazon boxes in preparation for the laser cutter for The Laboring Self exhibit and Return to Sender workshops, 2017-18. 


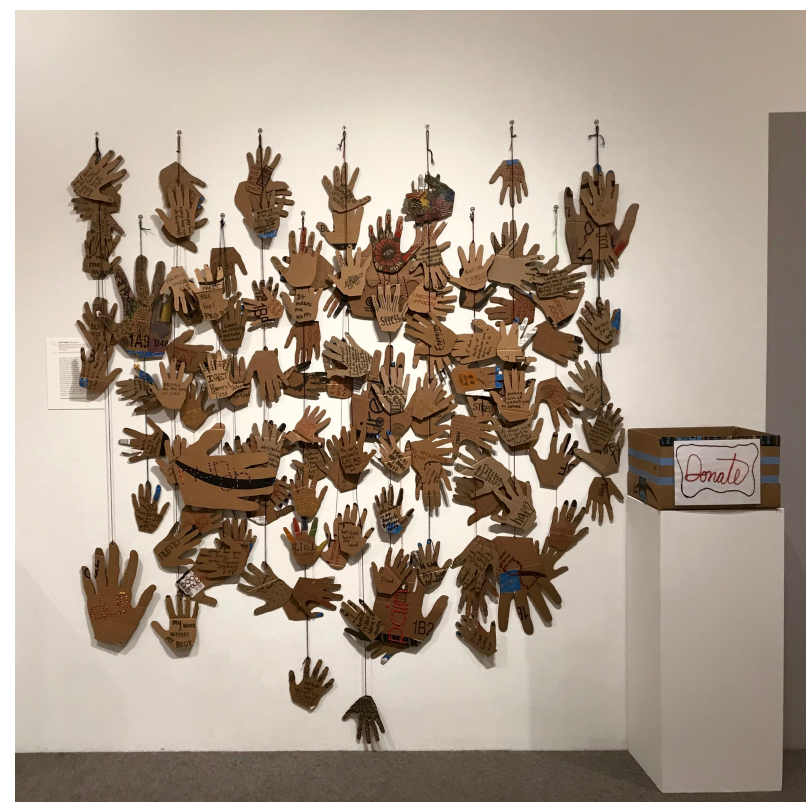

Figure 10. Embroidered cardboard hands-in the shapes of actual Mechanical Turk workers' hands - cut from Amazon boxes at the start of the exhibition in the Center for Creative Connections, October, 2017.

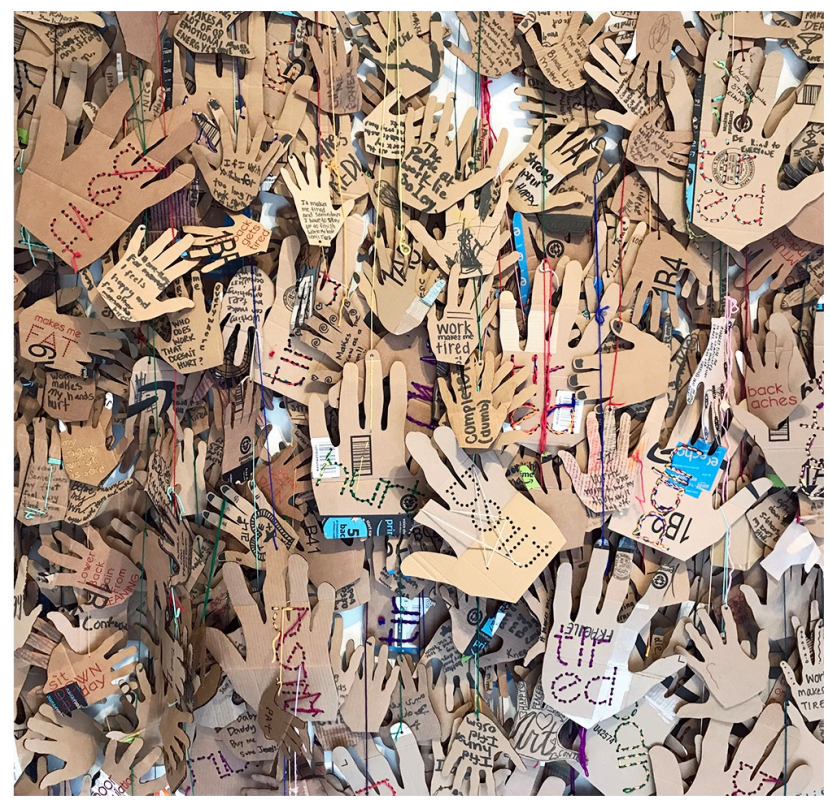

Figure 11. "Hired Hands" in The Laboring Self exhibit, 2017-18. The installation grew from about fifty that we generated in October to hundreds of hands made by participants through early January, 2018. 


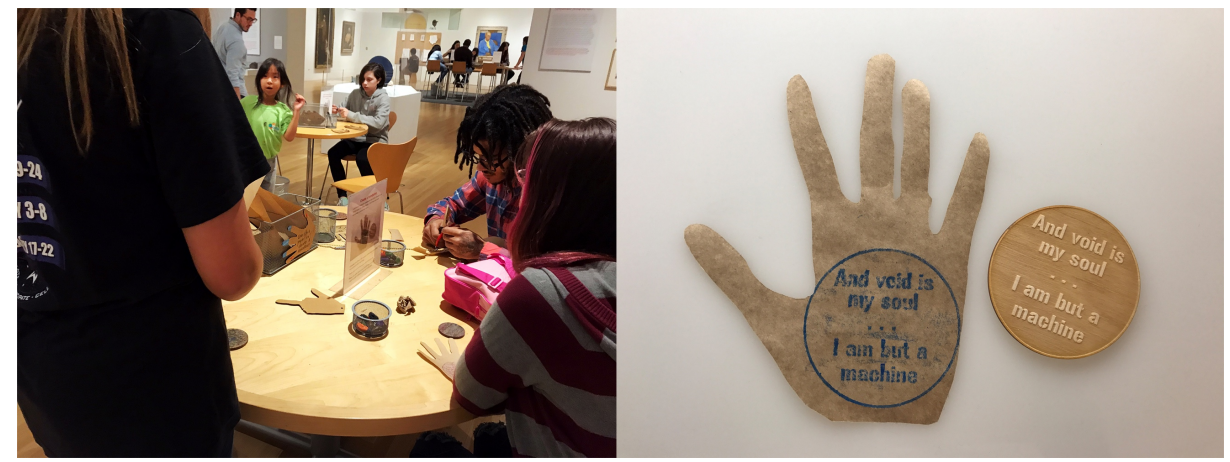

Figure 12. Participants trace their hands (left), and select a quote to rub onto their paper palms (right).

Next to "Hired Hands" were wall-mounted shadow boxes titled Illuminated Voices. Each box was connected to a wooden cut-out of an MTurk worker hand covered with conductive paint. Viewers were instructed to place their hand on the wooden hand cut-out (Figure 13). The physical connection made between the participant and the wooden hand closed the circuit inside the lightbox, where a long-form sentiment submitted by an MTurk worker was barely visible on white paper. These sentences about how work affects the worker body were stenciled, cut, and almost, but not quite, torn from the page. The tension of nearly being cut from the page, yielding white on white text, rendered the text difficult to read. When the circuit was closed, a strand of LED lights glowed inside the shadow box. When human interaction closed the circuit, the text inside became legible.

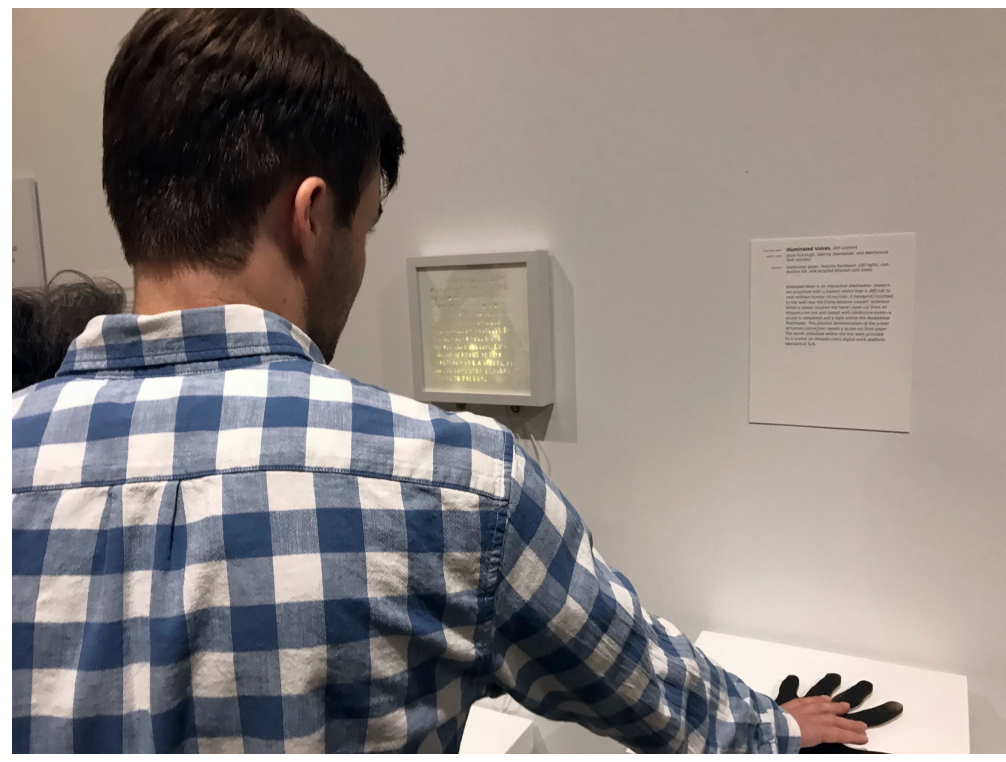

Figure 13. A participant places his hand on the wooden worker's hand to close the circuit in the shadow box. 
Lastly, ten monitors on the C3 media wall showcased informative, short videos that preemptively answered questions for visitors to the exhibition (Figure 14). For instance, Turker Tracings displayed original hand-traced images submitted by the workers, with an explanation of the virtual job board and how we arrived at a fair payment. Vectors demonstrated the process of tracing hands for the laser cutter.

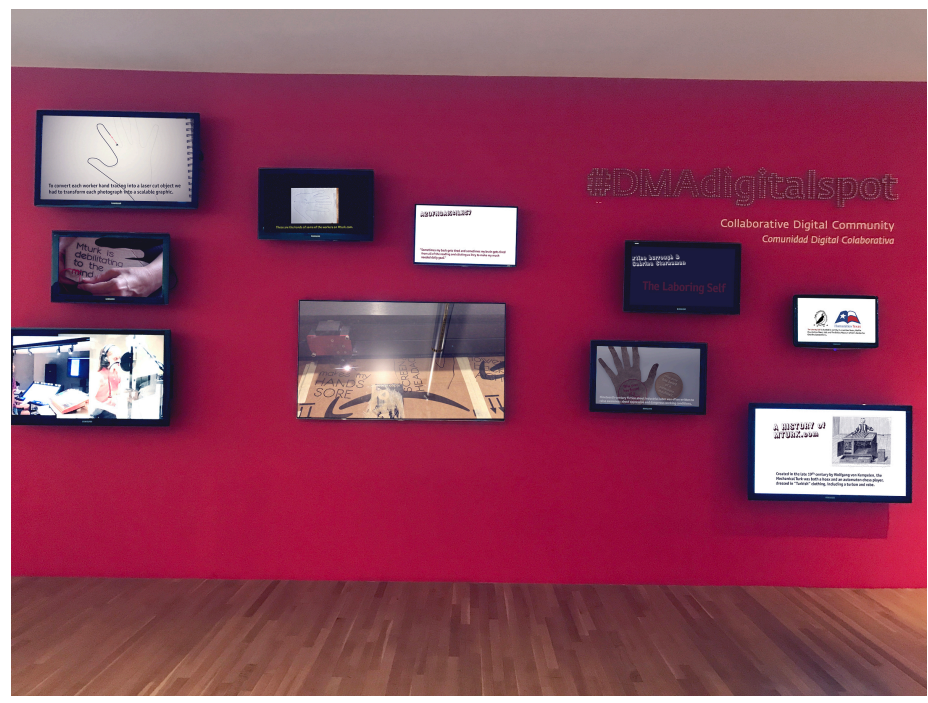

\section{Figure 14. The media wall in the Dallas Museum of Art's Center for Creative Connections showcases short videos that describe and explain The Laboring Self exhibit.}

Since this exhibition was participatory, and Starnaman and I are both educators, we saw another parallel—between the exhibition and workshop participants.

\section{Return to Sender}

Return to Sender is a workshop we created for participants in various groups connected to the Center, including the Teen Advisory Council and Meaningful Moments. We also presented it on university campuses across the US. Participants learned about MTurk and then worked in groups to create their own sentiment-collection job on Mturk.com (see Table 1). They developed questions for the workers that would lead to the kinds of sentiments we would send directly to Jeff Bezos on a Hired Hand (Figure 15).

We hired the MTurk workers in real time and had larger hands for embroidery during the time it took to receive results (Figure 16). Participants were challenged to agree on a payment fee for a short writing task. One group in Vermont paid the workers five cents, while another in California paid five dollars. After repeatedly sending hands to Bezos, and receiving no response, we decided that we could conduct this portion of the project electronically, on Instagram (Figure 17). While the questions varied at each workshop, reading the collection of hands as a text provides viewers with a chilling understanding of the workers' experiences (see Table 1). 


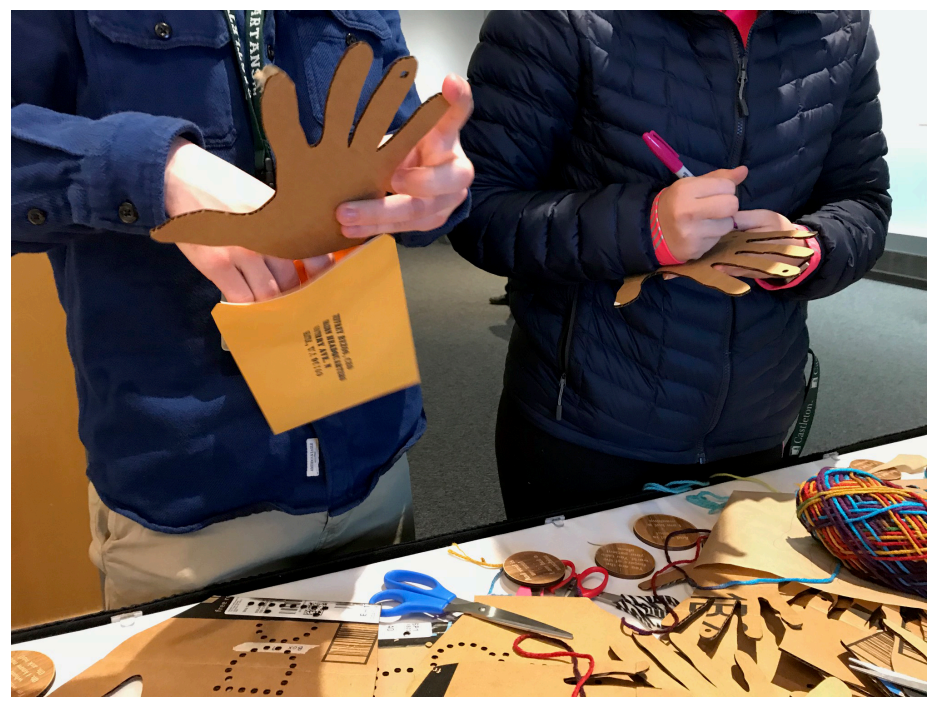

Figure 15. Hired Hands made at a Return to Sender workshop, on its way to Jeff Bezos' corporate address.

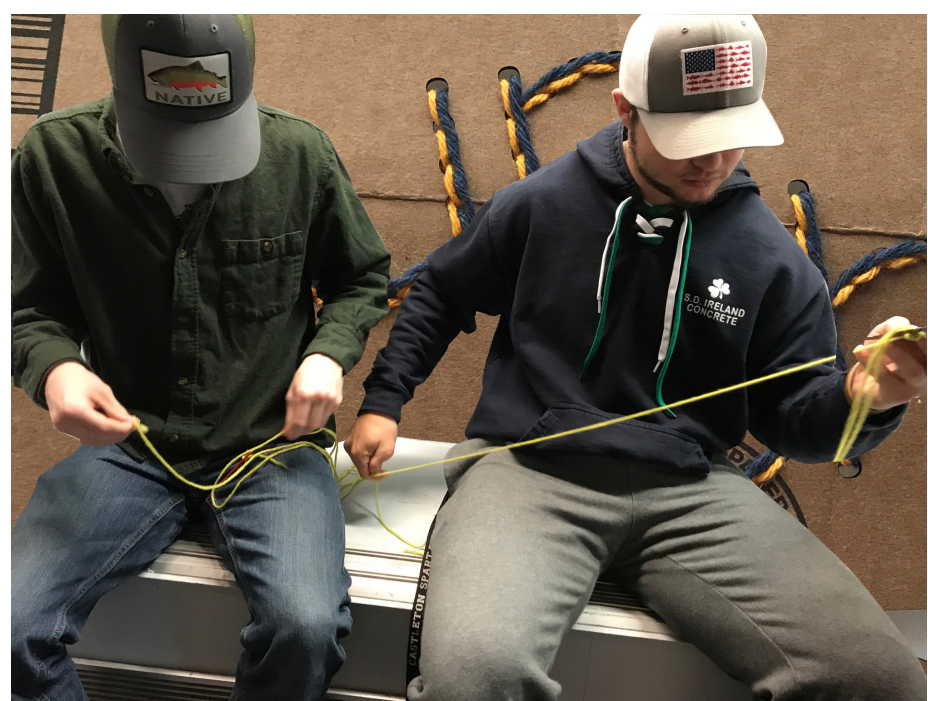

Figure 16. We were happily surprised by how much participants enjoyed embroidering these large hands each time we installed the exhibit or led a workshop. 


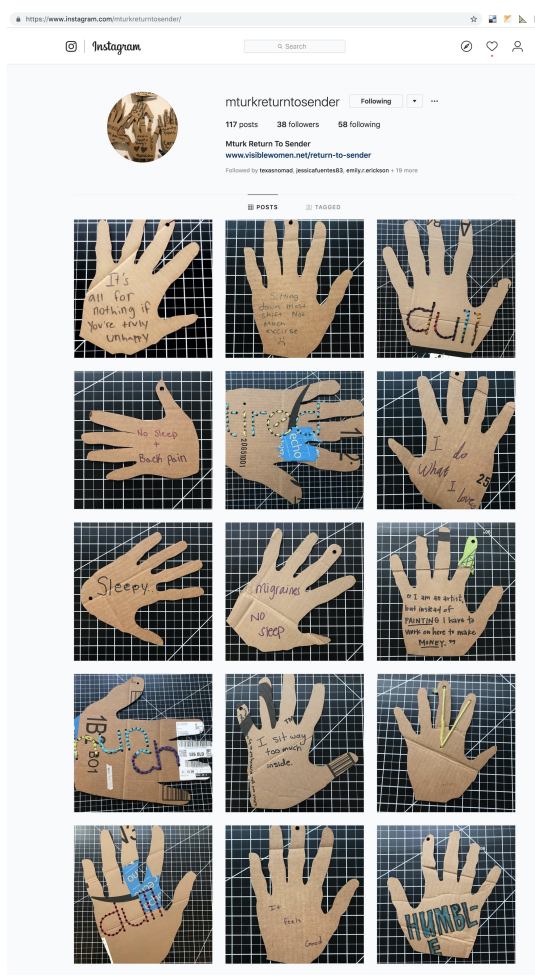

Figure 17. Our Instagram feed, mturkreturntosender, only displays (and archives) hands that were made in Return to Sender workshops.

Table 1. Sample Questions Posed to Workers by Return to Sender Workshop Participants, and Worker Responses

Note: All HITs began with wording such as, "Dear Turkers, We are creating a public intervention in which some of your responses may be included in an anonymous and artful mail project to Amazon headquarters. If you do not want to participate in something like this, please do not accept this HIT." Responses have not been edited.

\begin{tabular}{|c|c|c|c|}
\hline $\begin{array}{l}\text { Workshop } \\
\text { Location }\end{array}$ & Question & Pay & Sample Answer \\
\hline $\begin{array}{l}\text { The Onstead } \\
\text { Institute, } \\
\text { University of } \\
\text { North Texas, } \\
\text { Denton, Texas, } \\
\text { April 21, } 2018\end{array}$ & $\begin{array}{l}\text { 1. If you could prepare any } \\
\text { meal for your friends/family, } \\
\text { what would you prepare? } \\
\text { Describe the dishes. } \\
\text { 2. Take a picture of the place } \\
\text { where you gather for meals } \\
\text { (at work, at home, etc.). Share } \\
\text { your picture via Imagur, } \\
\text { Google Drive, Dropbox, etc., }\end{array}$ & $\$ 5.99$ & $\begin{array}{l}\text { I would prepare spaghetti with } \\
\text { Itallian sausage, its my favorite } \\
\text { meal with a red sauce. It doesnt } \\
\text { have to be complicated, just regular } \\
\text { grocery store itallian sausage, fry it } \\
\text { up in a pan, add it to the sauce, let it } \\
\text { simmer } 30 \text { minutes, make the } \\
\text { spaghetti (which ever is cheapest) } \\
\text { and boom pour over each other and } \\
\text { youre done. }\end{array}$ \\
\hline
\end{tabular}


please make sure the image is set to "public."

3. What topic would you introduce during meal conversation?

Note: The $\$ 5.99$ payment is equivalent to a U.S.

McDonald's Big Mac meal.

We may share your photo in a future publication.
https://imgur.com/a/QZ3okXo this is where me and my girlfriend share lunch every day

I would probably bring up politics

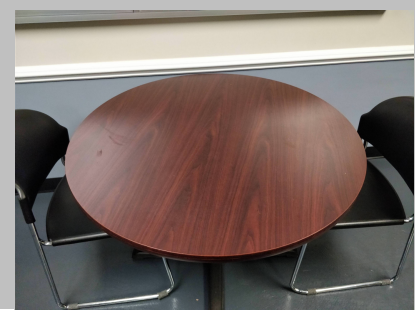

https://imgur.com/a/LpKU7Dr

Total $\$ 18$

Prime Rib - $\$ 10$

Asparagus $\quad-\quad \$ 3$

Yorkshire Puddings - $\$ 3$

Gravy

$\$ 1$

3. How much would it cost to make your meal in U.S. dollars?

We may share the photo of your drawing in a future publication.

California State 1. How dependent are you in University, San the virtual community as Marcos, March worker and consumer?

14, 2018

Castleton

University,

Vermont,

March 1, 2018
2. Does your work on Mturk enable you to participate as an Amazon consumer?

3. Do you have a Prime membership (it costs \$99)? How many hours would you have to work on Mturk.com to earn $\$ 99$ ?

1. What part of working on Mturk.com makes you happy?

1a. Have you ever thought about stopping work on Mturk.com?
$\$ 5.00$ 1. I am not dependent at all when it comes to working or consuming in the virtual community. 2. It could, however I take all my earnings out in cash via bank withdraw.

3. I do not have a Prime membership. It depends on the day, I would say on an average day about 7-8 hours.

\$0.05 I work on mturk because I have to take care of my mother who had a brain anyrism. It's a way I can stay home with her as she recovers (she's going in for brain surgery again in 2 weeks). I'd love to get a 
1b. What is a good reason for you to continue working on Mturk.com?

On average:

2. How many hours a week do you spend on mturk.com? 2a. How much time do you waste on HITs that are already closed? 2 b. How many jobs have you submitted that were rejected? real job again and I probably will too. I was a drifter for a few years before this happened and was doing it to survive, but now I don't really need to. I get annoyed with mturk due to low pay rate for high amounts of effort. I mean, I'm getting paid a nickle for this, but I always am like, well, at least it's something I guess. A little is a lot when you ain't got none. Plus, I'm being a caretaker for my mother and can leave at any time. No obligation.

I have mturk open all the time on my craptop laptop with auto refreshers on the jobs I like. I do other jobs too while it auto refreshes. Better to do be doing something rather then nothing. I'd say I work on mturk 20 hours a week, but it's open a good 70 hours.

There's so much bullshit on mturk now. Plus the things I've already done and the stuff I know is a scam. I've got 3200 rejections and about 3000 of those are readabl (I don't care if I get rejections to be honest.) I'd have to get another 5000 rejections + in order to be under 99\% I've got 820000+ approved. I'd say I waste a good 2-3 hours on stuff that's been closed or misleading or scams or whatever a week.

The "upgrade" they did also killed my production as well because I had to change my style. Anyway, mturk is a huge waste of time/money, but it's good for what I'm doing since I'd be making no money otherwise.

\section{Castleton} University,
1. What part of working on Mturk.com makes you
$\$ 0.35$ 1) Honestly, the interaction between the workers on the forums 


\begin{tabular}{|c|c|c|}
\hline $\begin{array}{l}\text { Vermont, } \\
\text { March 1, } 2018\end{array}$ & $\begin{array}{l}\text { happy? } \\
\text { 1a. Have you ever thought } \\
\text { about stopping work on } \\
\text { Mturk.com? } \\
\text { 1b. What is a good reason for } \\
\text { you to continue working on } \\
\text { Mturk.com? } \\
\text { On average: } \\
\text { 2. How many hours a week do } \\
\text { you spend on mturk.com? } \\
\text { 2a. How much time do you } \\
\text { waste on HITs that are } \\
\text { already closed? } \\
2 \text { b. How many jobs have you } \\
\text { submitted that were rejected? }\end{array}$ & $\begin{array}{l}\text { and such is always nice. It's nice to } \\
\text { have common ground with people } \\
\text { to talk about on forums, on top of } \\
\text { the money obviously. } \\
\text { 1a) Yes, at times. } \\
\text { 1b) Consistent income that pays for } \\
\text { my wants, and sometimes my needs } \\
\text { depending on the situation. } \\
\text { 2) I spend about } 25 \text { hours a week on } \\
\text { mturk. } \\
2 \text { a) I don't know if there's a way to } \\
\text { actually measure that. If I had to } \\
\text { guess, I'd say about an hour a day } \\
\text { on hits that are impossible to get/tell } \\
\text { me to return them or whatever. } \\
2 \text { b) I have had } 13 \text { rejections over the } \\
4 \text { years I've been doing mturk. }\end{array}$ \\
\hline
\end{tabular}

\section{Olympians discuss their jobs}

Just before the Winter Olympic Games of 2018 I was contacted by a journalist from Wired Magazine. Miranda Katz and I talked at length about projects that I discuss in this article, and other projects that are older or ongoing. She asked poignant questions about who I think the workers are, why they work, and what their experiences might be like in the projects I post. I told her about workers like Shamik Ghosh and "Marty McFly" (a YouTube handle), who participate in the Mechanical Olympics every two years.

When I set down the phone I thought it would be better if the workers, themselves, would answer her questions. I created a job targeted at workers who have been paid for their participation in the Mechanical Olympics.

For this job, I made a video diary entry that asked the workers to submit to me their own video diary entry in which they tell me about their experience as a Mechanical Olympian. I shared with them that my artistic intention for the project was to make a fun, creative, and embodied job, and I asked them to tell me how it was for them. Was it fun? Creative? Stress-inducing?

Ms. Katz circled back to me when her editor asked her to write a story only about the Mechanical Olympics, because of the timing of her request. ${ }^{16}$ By this time I was able to share with her the videos that I had collected, which she in turn noted in her article. ${ }^{17}$ She also contacted Shamik Ghosh, who 
I spoke about at length during our phone conversation. The interviews with Miranda reignited my interest in this project.

\section{Coda: A decade of work(ing) with the Ghosh in the machine}

\section{Dear Mr. Shamik Ghosh,}

I have never met you in person, but I feel deeply connected to you and your family. I have watched your son, Soham, grow from the first video I saw of him pretending to ride a bobsled for the Winter Mechanical Olympics in 2010. He was seven then, I know this because you added it to the description of the video on YouTube. I saw him again and again, and when he performed badminton for the Summer 2016 Mechanical Olympics he looked like a teenager (Figure 18). I have seen him perform through much of his childhood and I have noticed how he looks through the camera lens at you with his big, brown eyes. I think you must be a great father because he has been so willing to play along with you for all of this time. As a mother of six year-old boys now, I can only hope that my children, too, will play along within our family so nicely.
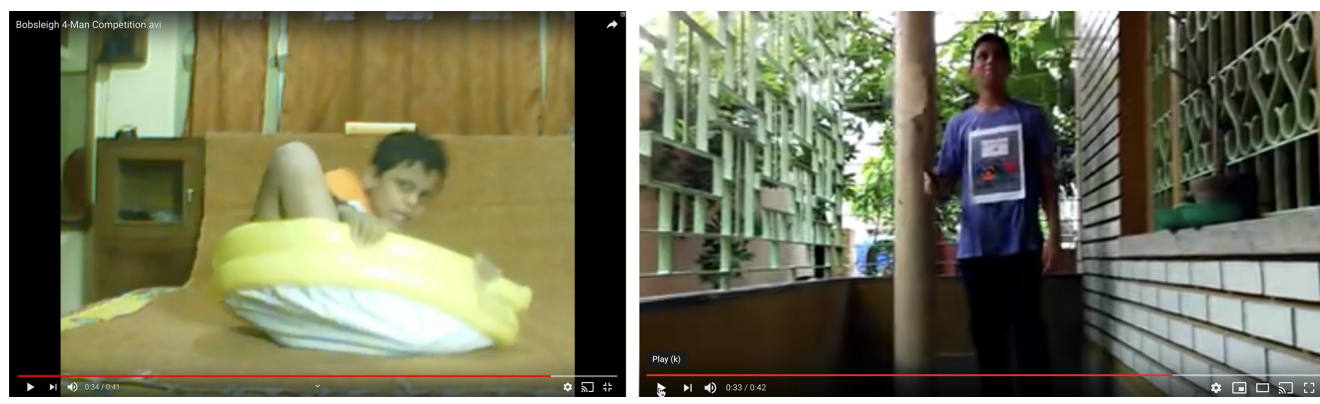

\section{Figure 18. Soham Ghosh performs the Mechanical Olympics at 7 and 13 years old.}

I watched you and your wife both perform curling-your version cleverly used a circular area on your patio as the destination for your winning sweep in the Winter Mechanical Olympics of 2018. Your wife's curling video was also filmed on the carpet in your house where you son was bobsledding in 2010 (Figure 19). It is strange that parts of your house are familiar to me, but I have been watching these videos and enjoying your participation in this made-up event for a decade. You wrote that Soham liked participating (at least when he was younger) because he liked to make funny videos. When I think about all of the reasons I had, or more like intuitions or curiosities that I had, for making this project, one of the guiding and simplest ideas was that it would be fun to ask people who work anonymously on the Mturk.com platform to make funny videos. 

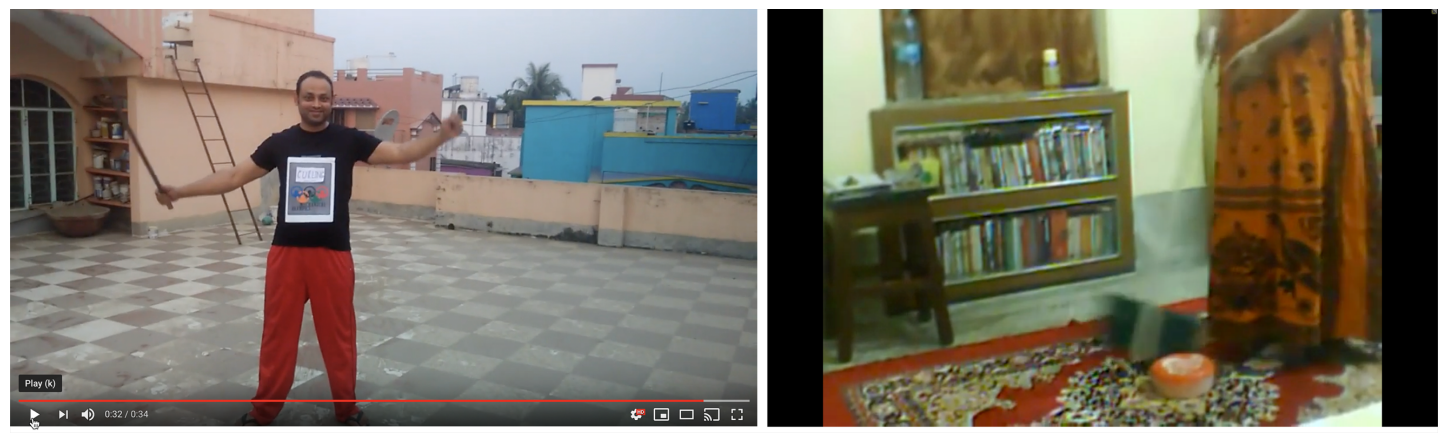

\section{Figure 19. Shamik Ghosh (left) and his wife (right) perform "Curling" for the Mechanical Olympics in 2018 (left) and 2010 (right).}

When Miranda Katz, a reporter from Wired, called me in 2018 I told her about several ongoing projects that I conduct on Mechanical Turk, and that there are some workers who follow my job postings. I recalled to Miranda that I was putting together a collection of videos for this project for the Dallas Museum of Art's video wall in August 2016 and doing that gave me an opportunity to watch all of the videos I had collected. It was not until then that I realized that I have been watching your family grow over all this time. Your name was familiar each year, but seeing the videos you made from 2010, '12, '14, and '16 all together made me realize just how much you and your family have been an important part of this project. If there is but one ghost in the machine that I wish I could reach out and hug, it would be the Ghosh family in Bengal, India. Thank you for your ongoing willingness to participate in this project.

Katz is a braver woman than I have ever been, seen in her ability to investigate and report out in the world while I turn inwards, speaking mainly to myself and maybe a few others who decode gestures and visualizations that represent tinkering — not reporting — with all the self-consciousness and doubt that pervades the artist's studio. As reporters do, Miranda Katz hung up the phone with me and quickly called you. I thought: You can just do that? She can do that. I, instead, am writing you a letter in a journal that you will unlikely see. ${ }^{18}$ Katz learned that you are an assistant high school teacher in Chakdaha and, like many workers on MTurk, you supplement your income with various online HITs. As I noticed, she confirmed that the videos are an opportunity for family bonding and that Soham looks forward to these fun video-making opportunities.

When I started this project, I wanted to see if people would do these funny jobs, and if workers wanted to, or would like to, get up and move around. I did not think the platform would be thriving a decade later, but I assumed that I would have some interesting, if vague, experiences with workers. Meanwhile, Amazon, in their Mechanical Turk platform (maybe in other arenas, too?) continues to be successful at perpetuating a mechanical approach to working online, where anonymity, speed, and accuracy prevail—perhaps at the expense of recognizing humans in community. I thought I would hack the platform for the workers, but I ended up hacking it for myself, too. Thank you for introducing me to the Ghosh family, who bring their intelligence, 
creativity, and playfulness to the Mechanical Olympics every two years. I can't wait to see your work in 2020.

Warmly,

xtine

\section{ACKNOWLEDGEMENTS}

For the Mechanical Olympics I would like to thank Marisa Olson for her upbeat review on Rhizome, early on, in 2008; and David Byrne for being one of the Webby judges in the year I placed as an Honoree in the "Weird" category for this project. I'd also just like to thank David Byrne in general (thanks, man). I am grateful to Miranda Katz at Wired Magazine for her thoughtful questions, and to the Ghosh family and all of the other worker-participants throughout the past decade. For the Mechanical Games, I thank Sarah Perks for understanding this project and translating it to fit the themes and audiences in the UK. Thank you to the Cultural Olympiad, the UK Big Lottery Fund, Abandon Normal Devices, All About Us, Arts Council England, Association of Greater Manchester Authorities, Let's Go Global, and (I know it is now defunct, but in my memory it lives on) Cornerhouse. That place was amazing. Thank you to Gaby Jenks, Debbie Chan, and Dean Brocklehurst who helped to produce the Mechanical Games the first time around for Abandon Normal Devices and to Paul Mayers who helped produce it for Looping the Loop in 2011. Much gratitude to all of the participants in the UK who played the Mechanical Games. For Mediations on Digital Labor, a heart-felt thanks to John Spiak, who helped me wrap my head around the project room when I was stuck in Amazon's cloud. Thank you to Mark Upson, who made just the right viewing station for that room, too. The Laboring Self exhibit and Return to Sender workshops would not have come to life without my collaborator Sabrina Starnaman and funding from Humanities Texas, from the Puffin Foundation West, Ltd., and from the School of Arts, Technology, and Emerging Communication at the University of Texas at Dallas. Thank you to my Dean, Anne Balsamo. Giant hug and thank you to Delaney Conroy, Letícia Ferreira, and Lizz Atwater. Thank you to Sam Green and Oliver Schemm at Castleton University and the Christine Price Gallery in Vermont, and to Lucy HG Solomon, Kate Crocker, and Talitha Matlin at California State University, San Marcos, for hosting us and allowing us to turn your students into activists on a Wednesday afternoon. Jeff Bezos, I'm not sure if I should thank you, but I'm adding your name here: \#jeffbezos, \#mturk, \#amazon.

\section{ENDNOTES}

1. See Meghna Chakrabarti, "The Origin Story of the Gig Economy," (WBUR, 2018). Dr. Emilia Istrate and Jonathan Harris, "The Future of Work the Rise of the Gig Economy," (2017), https://www.naco.org/featured-resources/future-work-rise-gig-economy. 
2. Aaron Koblin, "The Sheep Market," http://www.thesheepmarket.com. Koblin reports workers were paid an average wage of 69 cents per hour.

3. Julian Kücklich, "Precarious Playbour: Modders and the Digital Games Industry," Fibreculture Journal, no. 5 (2005).

4. Panos Ipeirotis, “The New Demographics of Mechanical Turk," (2010), https://www.behindthe-enemy-lines.com/2010/03/new-demographics-of-mechanical-turk.html. Joel Ross et al., "Who Are the Crowdworkers? Shifting Demographics in Mechanical Turk" (paper presented at the CHI 2010: Imagine all the People, Atlanta, GA, USA, 2010).

5. Ipeirotis, Ibid.

6. Jeff Crouse and Stephanie Rothenberg, "Invisible Threads" (paper presented at the Siggraph, Shenzhen, Guangdong, 2014).

7. Also, at this time the project was self-funded and I had to work with the budget I had allotted myself for it. I gave myself $\$ 200$ for tinkering on MTurk.

8. Marisa Olson, "Let's Get Physical," Rhizome (2008), https://rhizome.org/editorial/2008/aug/05/lets-get-physical/.

9. 2009 Honorees The Webby Awards, "Mechanical Olympics,"

https://www.webbyawards.com/winners/2009/web/general-website-categories/weird/mechanicalolympics/.

10. For instance, see: Jason Pontin, “Artificial Intelligence, with Help from the Humans," The New York Times (2007),

https://www.nytimes.com/2007/03/25/business/yourmoney/25Stream.html. Jonathan Zittrain, “The Internet Creates a New Kind of Sweatshop," Newsweek (2009),

https://www.newsweek.com/internet-creates-new-kind-sweatshop-75751. Katharine Mieskowski, "I Made \$1.45 a Week and I Love It," Salon (2006),

https://www.salon.com/2006/07/24/turks_3/. Alana Semuels, "The Internet Is Enabling a New Kind of Poorly Paid Hell," The Atlantic (2018),

https://www.theatlantic.com/business/archive/2018/01/amazon-mechanical-turk/551192/. Nancy Folbre, "The Unregulated Work of Mechanical Turk," (2012),

https://economix.blogs.nytimes.com/2013/03/18/the-unregulated-work-of-mechanical-turk/.

11. "Digital Labor," https://digitallabor.org/.

12. In 2014-15 I had infant twins who were one-and-a-half years old. Taking care of them was everything. I turned to meditation, relaxation, and a nightly dose of familiar "Seinfeld" reruns that aired at 10 and 10:30, right before I fell asleep. I know this project was influenced by a dreamy synthesis of these parts of my life, because the daytimes were full of a constant rotation of baby feedings, burpings, changings, rockings, cleanings, chasing them when they started to walk and run (one of them only ran), and occasional teaching.

13. We paid $\$ 3.50$ for this first job on Mturk.com, but we also included the question: Do you think you were paid fairly for this job? Four of the workers answered the question: one agreed it was fair payment, one suggested $\$ 2.00$ would be fair and $\$ 3.50$ was more than fair, one requested $\$ 4.50$ and one requested $\$ 5.00$. We could see that the longest time to completion was just over 22 minutes, and the shortest about 10 and a half minutes. On average, it took these workers just 
under 15 minutes to complete the job, so we decided that we would give each worker a bonus payment of fifty cents and then offer $\$ 4.00$ for the job (approximately $\$ 16 /$ hour, a little over the notion of a $\$ 15 /$ hour living wage in the US in 2017) when we offered it to one hundred new workers.

14. Honey \& Death, Dotline Font, 2007.

15. For instance, we included the line "Who ever has heard of a conscious machine?" from Morris Rosenfeld's 1914 poem, "In the Factory" (7). We included a quote from Elizabeth Phelps' 1871 book, The Silent Partner: "You are the fingers of the world. You take your patient place" (71). We also included quotes from renowned anarchist Emma Goldman.

16. Miranda Katz, "The Quest to Recreate the Olympics with Mechanical Turk," Wired (2018), https://www.wired.com/story/mechanical-turk-olympics/.

17. I paid $\$ 10.00$ for each of them, and requested only four. One is already offline, but three are still available.

18. (... and so here I promise to send this to you through the MTurk platform once it is sharable.)

\section{REFERENCES}

Brouwn, Stanley. “This Way Brouwn.” Konrad Fischer Galerie, 1962.

Chakrabarti, Meghna. "The Origin Story of the Gig Economy.” WBUR, 2018.

Crouse, Jeff, and Stephanie Rothenberg. "Invisible Threads." Paper presented at the Siggraph, Shenzhen, Guangdong, 2014.

"Digital Labor." https://digitallabor.org/.

Folbre, Nancy. "The Unregulated Work of Mechanical Turk." (2012). Published electronically March 18, 2013. https://economix.blogs.nytimes.com/2013/03/18/the-unregulated-workof-mechanical-turk/.

Helguera, Pablo. Education for Socially Engaged Art: A Materials and Techniques Handbook. Jorge Pinto Books, 2011.

Honey \& Death. "Dotline Font.” 2007.

Ipeirotis, Panos. "The New Demographics of Mechanical Turk." (2010). Published electronically March 9, 2010. https://www.behind-the-enemy-lines.com/2010/03/new-demographics-ofmechanical-turk.html.

Istrate, Dr. Emilia, and Jonathan Harris. "The Future of Work: The Rise of the Gig Economy." (2017). Published electronically November 2017. https://www.naco.org/featured-resources/futurework-rise-gig-economy

Julian, Kücklich. "Precarious Playbour: Modders and the Digital Games Industry." Fibreculture Journal, no. 5 (2005).

Katz, Miranda. "The Quest to Recreate the Olympics with Mechanical Turk." Wired (2018). Published electronically February 18, 2018. https://www.wired.com/story/mechanicalturk-olympics/.

Koblin, Aaron. "The Sheep Market." http://www.thesheepmarket.com.

LeWitt, Sol. “A Wall Drawing Retrospective.” MASS MoCA, 1969-2007. 
Markham, Annette N. Life Online: Researching Real Experience in Virtual Space / Annette N. Markham. Ethnographic Alternatives Book Series ; V. 6. Walnut Creek, CA: Altamira Press, 1998.

Mieskowski, Katharine. "I Made \$1.45 a Week and I Love It." Salon (2006). Published electronically July 24, 2006. https://www.salon.com/2006/07/24/turks 3/.

Olson, Marisa. "Let's Get Physical." Rhizome (2008).

https://rhizome.org/editorial/2008/aug/05/lets-get-physical/.

Phelps, Elizabeth Stuart. The Silent Partner. American Culture Series ; Reel 200:6. Boston: J.R. Osgood, 1871.

Pontin, Jason. "Artificial Intelligence, with Help from the Humans." The New York Times (2007). Published electronically March 25, 2007.

https://www.nytimes.com/2007/03/25/business/yourmoney/25Stream.html.

Rosenfeld, Morris. Songs of Labor and Other Poems. Translated by Rose Pastor Stokes and Helena Frank. Boston, MA: The Gorham Press, 1914.

Ross, Andrew. "In Search of the Lost Paycheck." In Digital Labor : The Internet as Playground and Factory, edited by Trebor Scholz. New York: Routledge, 2013.

Ross, Joel, Lilly Irani, M. Six Siberman, Andrew Zaldivar, and Bill Tomlinson. "Who Are the Crowdworkers? Shifting Demographics in Mechanical Turk." Paper presented at the CHI 2010: Imagine all the People, Atlanta, GA, USA, 2010.

Semuels, Alana. "The Internet Is Enabling a New Kind of Poorly Paid Hell." The Atlantic (2018). Published electronically January 23, 2018.

https://www.theatlantic.com/business/archive/2018/01/amazon-mechanical-turk/551192/.

The Webby Awards, 2009 Honorees. "Mechanical Olympics."

https://www.webbyawards.com/winners/2009/web/general-website-

categories/weird/mechanical-olympics/.

Zittrain, Jonathan. "The Internet Creates a New Kind of Sweatshop." Newsweek (2009).

Published electronically December 7, 2009. https://www.newsweek.com/internet-createsnew-kind-sweatshop-75751.

\section{AUTHOR BIO}

xtine burrough values the communicative power of art-making as a vehicle for exploring the boundaries between humans and the technologies they create, embody, and employ. Appropriation, juxtaposition, and computation are central to her practice as a hybrid artist. She plays at the intersection of media art and digital poetry.

burrough collaborates with diverse populations from students to senior citizens to virtual factory workers. Her projects yield multiple layers for various forms of participation in the creation of poetic moments of tactical media. She archives her work and process in articles, chapters, and books, in order to further articulate the relationships between what she makes and does with how 
she thinks about technology and culture. burrough uses remix and appropriation as strategies for activism and speaking back to structures of power, and she has edited volumes and portfolio sections where other artists can write, reflect on, expose, and archive their practices.

burrough is Area Head of Design + Creative Practice in the School of Arts, Technology, and Emerging Communication at UT Dallas, where she organizes LabSynthE, a laboratory for creating synthetic, electronic poetry. The second edition of her book, Foundations of Digital Art and Design with Adobe Creative Cloud, is newly available for fall 2019. 